\title{
Spreading the word: how public libraries are helping to extend digital inclusion
}

\author{
Lindsay McKrell
}

\begin{abstract}
Public libraries are on the frontline in the battle to engage those lacking IT skills, offering free access to the internet and support where required. The range of services available online has increased exponentially in the last few years to the extent that those without IT skills are at a considerable disadvantage. This has been recognised by governments at UK, Scottish and local authority level and the push to offer basic training is on. Public libraries have a vitally important role to play in encouraging citizens to meet their full potential, by opening up access to information, education, employment and entitlements only available online. Bridging the crucial skills gap cannot be achieved without significant investment in the hardware, software and staffing public libraries provide. Properly resourced, they are uniquely placed to meet growing demand.
\end{abstract}

\section{Introduction}

Access to the internet is increasingly important for the modern citizen. There has been a seismic shift in consumer activity from the high street to the tablet. Many government services are offered online by default as physical offices close and telephone helplines jam. Information is accessible as never before, and the huge quantity and variable quality of what is available means that new skills are required to find the right information in the pile.

Those who do not have access to the internet will lose out. Crucially, those who lack the skills to navigate, evaluate and use the information it makes available will be no better off. Libraries are faced with the challenge of solving both these problems - digital access and information literacy. Perhaps together they add up to one big problem - digital inclusion, and it is not a problem we can solve alone.

\section{Author}

Lindsay McKrell BA, MSc, PGDip, PhD is Community Librarian (City) with Stirling Council Libraries and a Committee Member of the Information Literacy Community of Practice. She is writing in a personal capacity in this article and expressing her own views.

Email: mckrelll@stirling.gov.uk. 


\section{Scottish Library and Information Council (SLIC)}

The Scottish Library and Information Council (SLIC) is the advisory body to the Scottish Government on library matters and has been working to ensure libraries are represented in the national digital strategy. It has worked closely with the Digital Participation Team in the Scottish Government's Digital Directorate and has been awarded funding for two projects in the last year.

The first of these is an online resource to map PC access and training opportunities in libraries. Members of the public will be able to search the Digital Scotland database by postcode to see what computer classes are available in their area and these courses will be promoted.

The second project funded a temporary Digital Project Officer for libraries, working between SLIC and the Scottish Government. Lynne Swan was appointed to this role.

Lynn conducted a review of digital learning opportunities in Scottish public libraries and produced a major report outlining basic internet course availability. She identified the need for resources and training to extend this work. The Landscape paper Scottish Libraries - supporting digital participation (SLIC, 2013) was approved by the Heads of Public Library Services in Scotland and will shape future work.

In line with the report's recommendations, SLIC aims to produce proposals for a more consistent Scottish libraries offer for computer courses and a national training programme for staff. It has also identified a Digital Champion for each local library service to liaise and assist with delivering these initiatives.

I am the Digital Champion for Stirling Council Libraries and Archives and attended the Inaugural Meeting of the Scottish Libraries Digital Participation Group in October 2013.

\section{Scottish Libraries Digital Participation Group}

At the first meeting of this group we heard the Scottish Government's vision of Digital Participation from a member of the Digital Directorate. Moira Methven, interim Chief Executive at SLIC, highlighted the digital divide in Scotland, where $22 \%$ of the Scottish population are not internet users. Gillian Hanlon, also of SLIC, spoke about the mapping exercise gathering data for the online database and Lynne Swan introduced the SLIC Landscape paper.

In setting the scene, Lynne highlighted pressure from Government to extend digital participation. This includes the UK Government's Digital by Default programme aiming to transform 25 key services and the introduction of Universal Credit, which will require claims to be made online. Libraries are already feeling increased demand from jobseekers required to use the Universal Jobmatch site. The rollout of Universal Credit will bring in a whole new range of customers who lack confidence using IT. They will have to complete lengthy benefit claim forms to access the money they are entitled to and this could be a stressful experience for staff and users alike. 
The Scottish Government plans to widen its delivery of public services by adopting a "digital first" service design which means that public sector organisations will deliver online everything that can be delivered online - Stirling Council has a Channel Shift programme which will implement this change.

Added to pressure from Government at all levels is the increasing demand from employers for candidates to have IT skills, and the growing expectation that applications should be completed online.

In 2000, faced with a similar surge in demand, a $£ 100$ million People's Network programme equipped public libraries throughout the UK with computers and internet connections and $£ 20$ million was spent training library staff. However, no further funding has emerged to replace ailing PCs or refresh training to keep pace with changes in ICT and the Network is feeling the strain. There also needs to be investment in new devices, tablets and smart phones, and moves to include these in training for staff and public.

There has been smaller scale finance for innovation since then. The Scottish Government Public Library Improvement Fund (PLIF) is a $£ 500,000$ per annum fund managed by SLIC which aims to encourage service development in local authorities. This funding has resulted in examples of good practice which were presented in SLIC (2013) at the meeting, and it is worth mentioning a few of them here:

- Clackmannanshire has an online work club. The Library ICT tutor worked with JobCentre Plus to develop an ICT skills programme for the unemployed and those looking for volunteering opportunities.

- Inverclyde have developed online workforce training on newer technologies and social media following a staff skills survey and this has been very well received.

- Glasgow Libraries manage a range of ICT courses from beginners' level to the European Computer Driving Licence (ECDL). They have 15 dedicated tutors and test centres available and also work closely with JobCentre Plus and local housing associations. They offer a three-hour crash course for jobseekers, including an introduction to mouse and keyboard, creating an e-mail address and completing the online form in Universal Jobmatch.

There were 36 Public Library Quality Improvement Matrix (PLQIM) funded projects related to digital participation and it is hoped these will be further reviewed and used to share best practice.

Presentations on the day and discussion on the floor found common ground and few surprises. The problems identified included:

- Large numbers of the population lacking PC access;

- Great expectations from Government;

- Employers recruiting exclusively online;

- Unemployed and benefit claimants needing to apply online and lacking the skills to do so; 
- Crumbling IT infrastructure - hardware and software out of date, poor connectivity;

- Lack of staff resource to meet demand;

- A need for new training programmes to increase staff confidence in accessing services online and through different devices.

\section{Local level - a Stirling Solution?}

Stirling's Community Planning Partnership hosts an interagency Digital Inclusion group as part of a wider Tackling Poverty workstream. This includes:

- representatives from Stirling Council such as:

○ Adult Learning Team;

○ Community Engagement;

○ Community Planning and Regeneration;

○ Housing;

○ Employability;

○ Social Services.

- national agencies such as:

○ JobCentre Plus / Department of Work and Pensions (DWP);

- Citizens Advice Bureau (CAB);

○ Skills Development Scotland;

○ Shelter.

- local bodies such as:

○ Stirling Voluntary Enterprise;

- Council on Disability;

○ Forth Valley College;

○ Paragon Housing;

- Cultenhove Opportunities Partnership;

○ Raploch Community Enterprise;

○ Raploch Community Partnership

○ ACE Cornton.

This seems to be a huge array of organisations but the reality is that all of our users are affected by Welfare Reform and the shift to digital by default. I and my colleague Victoria McAra, who is Community Librarian for the Rural Libraries in Stirling, attend this group.

In a similar approach to the Digital Participation Group at national level, this local group has mapped what provision already exists, starting with PCs themselves. 
Libraries emerged as the largest provider here with over 100 PCs spread across an extensive and geographically diverse area. As in the national group, meetings revealed a wide variety of training offered by different organisations, and again, there is a challenge to inform all involved, staff and users, about what is available. A sub-group is now working on a basic leaflet with signposting information which Libraries will design and circulate, as well as a Council webpage with links to all relevant organisations.

New services have been set up in response to demand, often on a partnership basis. So the Adult Learning Team now offers a literacy support group and an English for Speakers of Other Languages (ESOL) group, both meeting at the Job Centre on a weekly basis and helping jobseekers with particular needs. Libraries can refer people to these.

All partners expressed similar concerns to those mentioned at the Glasgow meeting, chiefly increased demand, ageing PCs and the need for basic IT training to allow people to access government sites and create their own accounts. Jobcentre Plus do not have an official policy of referring people to libraries, their practice is to assess the IT skills of each new client they take on and offer training if required. Somehow, people keep turning up in libraries saying they have been referred.

Many Stirling Libraries have one member of staff and a high proportion of Community Library Officers work only the hours their library is open. The business of running the library means they do not always have time to deliver one to one training. Offering help and meeting other demands can be a challenge.

We have established a weekly drop-in with an Adviser from JobCentre Plus in attendance at Bannockburn Library, which has experienced the greatest demand for help, and this has worked well. In addition:

- We have advertised for volunteers and are recruiting them now;

- We are continuing the partnership work we have always done;

- A weekly Jobclub is delivered by the CAB at Cowie and Plean Libraries;

- A new Jobclub with advice surgery is starting fortnightly in Callander Library;

- Computing for Employability classes at Central and Bannockburn;

- Regular Flexible learning sessions are supported by Forth Valley College who will help people set up e-mail accounts on request;

- Computer classes from basic to advanced are provided by the Adult Learning Team.

In the Stirling area, there are large numbers of computers available in projects in Raploch and Cornton as well as those in libraries. The training and help available in each centre are slightly different.

Stirling Libraries have recently been approached by Stirling Voluntary Enterprise (SVE). SVE is leading a bid with JobCentre Plus for Flexible Support Funding to organise basic level IT courses aimed at the unemployed. The Flexible Support Fund is money administered by Job Centre Plus (JCP) to help reduce barriers to 
people accessing employment. While this can be applied for by individual JCP customers for help with costs such as travel to interviews, a partnerships element can be awarded to organisations who want to run programmes in partnership with JCP to support Jobcentre customers either to get into work or to become closer to the labour market. Partners in Raploch and Cornton and Forth Valley College are also involved. As well as basic computing, learners will be helped with selfdevelopment and confidence building. They will be given the chance to produce $\mathrm{CVs}$ and will have guaranteed interviews at the end of their course. This is very much based on the model in Clackmannan mentioned earlier in this paper. The courses will be voluntary for participants and will be offered in libraries and other venues.

Stirling CAB is keen to offer financial inclusion as part of the offer. This would include money advice, help with fuel poverty and debt and the opportunity to join a credit union.

Prospects look good and if funding is approved, 24 courses will run throughout the Stirling Council area for ten months from the end of March. Almost three hundred people would have access to this training. Drop-in help could be offered in addition to this and all agencies involved would increase signposting to colleges and volunteering opportunities.

Stirling does not have a dedicated ICT tutor in the way that Clackmannan does and therefore cannot offer to deliver training, but we are keen to be involved in a well-organised project reaching all parts of the Council area.

\section{A core offer?}

The model outlined above might not be possible for everyone, and might not work for some. It arose from the local Digital Inclusion group in Stirling which has been through a similar process to the Digital Participation Group organised by SLIC. We began by mapping our resources and then developed a plan for how best to use them. A history of working in partnership has helped this along.

Partnership working is key, because as outlined at the start of this paper, we cannot foster digital inclusion alone. Public libraries have a long and proud tradition of working in partnership with other statutory, voluntary and community-based organisations, and it is the secret of our success. This work pools expertise and clientele and avoids duplication. But it does come in different shapes, and each library service will work successfully with different partners.

SLIC's Landscape Paper argues for a "core/consistent Scottish libraries offer for basic Internet training provision" (SLIC, 2013). It outlines the wide range of models operating currently. Some services employ ICT tutors, many do not. Some work in partnership with local colleges, others with JobCentre Plus. Funding and facilities differ hugely. Is it possible to create a national minimum standard of provision given the variety of resources and ways of working outlined above? Basic internet training is being offered in some way in all library authorities, which must be a positive in itself. An injection of funding would increase the offer across the board. 
The problems of ageing PC infrastructure and connectivity have been emphasised above. Further problems are posed by budget pressures in many local authorities. In some cases these have resulted in reduced staffing levels and cuts to opening hours. While the spirit is willing, the body is weak. What a difference it would make if funding could support an ICT/tutor co-ordinator in every authority. How incredible would it be to have replacement PCs, fit-for-purpose software and new devices to spread the word about the internet and all it offers? Imagine what we could achieve with funds for relief staffing so that library staff could spend time helping local people in their libraries without having to worry about queues at the desk?

The team of Digital Champions can do a great deal to coordinate new initiatives and communicate what happens in their area. That will improve what we can provide overall. However, a unified model could not be achieved without significant central funding.

\section{The POW Factor}

The UK and Scottish Governments might decide that such funding would bring returns. Public libraries are uniquely placed to increase digital inclusion. They have the POW Factor - the Potential, Opportunity and Workforce to can get results:

- Potential:

- There are over 500 public library branches across Scotland as well as mobile libraries;

- Sometimes a library is the only Council service present in a community;

○ They are seen as safe, neutral places to go for information, leisure and learning;

- PC access is free and most authorities offer free wifi too;

- There is a great willingness from libraries to meet demands for help and to adapt to the new pressures as best we can;

- Libraries working in partnership can offer a mix of skills, venues and resources to suit all circumstances.

- Opportunity:

- Changes to welfare reform and the move to digital by default will result in a whole new range of people coming through our doors. This is our chance to recruit them as library users and as learners. Some people who come in to get an e-mail account leave with a library card and a list of courses they can follow up. Many will return to use computers and ask for help;

- Libraries are increasingly co-located with other Council services, GP practices, tourist information or advice services. New people coming in represent an opportunity for these services too and 
signposting might naturally occur. Working closely together might increase customers all round;

- Workforce:

- Staff members are enthusiastic and interested;

- They are sensitive to the needs of learners, especially those who lack confidence;

○ They have exceptional customer service skills and the patience to explain how things work;

- Library staff are fully aware of data protection concerns and the need to respect confidentiality;

○ They are skilled in signposting to other agencies when required.

\section{Conclusion}

As always, libraries are making the best of a difficult situation, working with others, promoting what we have. We can boast a vast network of PCs and welltrained, motivated staff, which is exactly what the wider workforce needs. It is essential that people feel confident using ICT, and that they can use it successfully. Public libraries are already responding to demands from help from users wary of engaging with IT, passing on knowledge and encouraging the development of new skills. Libraries are in the frontline fighting the digital divide at this most crucial time. Co-ordinating the troops will be a huge step forward in the battle. With a little more investment, we might win.

\section{References}

SLIC (2013). Scottish Libraries - Supporting Digital Participation.

\section{Open access and copyright}

Library and Information Research is an open access journal. A freely available copy of this paper may be downloaded from the journal's website: http://www.lirgjournal.org.uk.

Copyright and associated moral rights in works published in Library and Information Research are retained by the author(s) but this paper may be used freely, with proper attribution, in educational and other non-commercial settings. 